\title{
O ENSINO MÉDIO: A CULTURA CORPORAL DE MOVIMENTO E AS CULTURAS JUVENIS NA ESCOLA
}

Kelly da Silva Oliveira, Márcia Regina Canhoto de Lima, José Milton de Lima, Lucas Silvestre dos Santos

Educação Física, departamento de Educação Física, Universidade Estadual Paulista - FCT Presidente Prudente, kellyletrasunesp@gmail.com, financiamento RENOVE.

\section{RESUMO}

Esta pesquisa buscou investigar quais são as manifestações das Culturas Juvenis relacionadas à Cultura Corporal de Movimento, como são vivenciadas pelos jovens-alunos de uma escola do Ensino Médio da cidade de Presidente Prudente e de que forma dialogam com a disciplina de Educação Física. Buscamos suporte teórico na Sociologia da Juventude aproximando-a dos princípios da produção de Paulo Freire. A metodologia adotada foi de natureza qualitativa, caracterizada como pesquisa intervenção. Como resultado, pudemos obter o perfil dos jovensalunos com relação as suas manifestações juvenis dentro e fora do ambiente escolar. Também, foi possível afirmar que a disciplina de Educação Física pôde realizar um diálogo integrativo com as culturas juvenis no espaço escolar. A partir da valorização das manifestações juvenis a escola adquire um novo significado para os jovens, deixa de ser um local desestimulante e passa a ser uma extensão dos espaços juvenis, um local onde também de produz cultura.

Palavras-chave: Educação Física, Cultura Corporal de Movimento e Culturas Juvenis.

\section{INTRODUÇÃO}

Atualmente há muitos questionamentos em relação ao desinteresse dos jovens pela escola, são inúmeras as suposições que surgem para explicar a "revolta" juvenil. Estudos sobre a temática da juventude vêm ganhando espaço nas Academias, mas ainda é comum a visão estereotipada do jovem, acreditando que essa fase é marcada pela revolta, conflito e rebeldia, numa vertente naturalista e universal.

Atualmente, percebemos que a escola representa para o jovem um espaço marcado pelo conservadorismo, autoritarismo e repressão, essa é uma das causas da evasão escolar. Estudos sobre os jovens e seu relacionamento com a escola apontam para o que Paulo Carrano (2009, p. 159) denomina de: "situação de incomunicabilidade entre os sujeitos escolares".

Para a realização da pesquisa foi necessário compreender de que forma a escola auxilia o jovem no processo de socialização, no seu processo de construção de identidade e de emancipação humana e como tal instituição considera ou não as manifestações juvenis.

Ao iniciar os estudos sobre juventude é possível perceber o quão complexa esta é. Diante de infinitas possibilidades de análise, de compreensão e de pontos de vista, pode-se notar que há "juventudes" e não juventude, elas são muitas, cada qual com sua particularidade. 
A escola é um espaço de conflitos, de (des) encontros, de identidades, opiniões, ideologias, enfim, podemos dizer que uma instituição com tantas responsabilidades seja de fato um espaço multicultural. É preciso considerar as manifestações juvenis e dar devida importância às mesmas para que possamos construir uma sociedade mais humana e justa. Sobre essa estreita relação entre jovens e transformações sociais Reguillo esclarece:

La juventud es una categoría construida culturalmente, no se trata de una "esencia" y, en tal sentido, la mutabilidad de los criterios que fijan los límites y los comportamientos de lo juvenil, está necesariamente vinculada a los contextos sociohistóricos, producto de las relaciones de fuerza en una determinada sociedad. (REGUILLO, p. 104, 2003)

Dentro desse espaço multicultural, ideológico, formador de seres humanos que é a escola encontramos os jovens, vivendo um momento de decisões na vida pessoal, além de tantas outras mudanças físicas que muitas vezes acompanham esse momento. Por esses motivos é que é tão importante considerar suas expectativas, anseios, dúvidas, afinal, uma educação problematizadora como defende Paulo Freire é aquela que forma o ser completo.

Buscamos, por meio da educação, instigar nos alunos a reflexão crítica e dessa maneira levá-los a se tornar sujeitos atuantes e conscientes na sociedade. Para alcançar tal meta, nossa proposta foi realizar um diálogo entre a escola, os saberes escolares e os jovens com suas expectativas e manifestações.

Segundo o sociólogo Pais (2006, pg. 07), "há duas diferentes maneiras de olharmos as culturas juvenis: através das socializações que as prescrevem ou das suas expressividades (performances) cotidianas".

Pais (1990) compreende a juventude não como uma fase de transição, uma fase de vida em que as pessoas têm que necessariamente passar em todas as sociedades, mas usa o termo "curso de vida". Para o autor (1990, p. 146), "a segmentarização do curso de vida em sucessivas fases — a juventude aparece associada a uma delas - é, por conseguinte, produto de um complexo processo de construção social".

Nesse sentido, esta pesquisa vem com a intenção de desconstruir essa visão de juventude concebida como entidade homogênea. Segundo Pais (2003), as diferentes formas de conceber a juventude são agrupadas de acordo com diferentes teorias, compreendidas em duas principais correntes que são: a geracional (aborda a juventude referida a uma fase da vida e consequentemente a um aspecto unitário, a principal discussão refere-se à continuidade e 
descontinuidade dos valores intrageracionais) e a classista (aqui as culturas juvenis são sempre culturas de classes, compreendidas como produto das relações antagônicas de classe).

José Machado Pais não opta por uma ou outra corrente, o sociólogo coloca-se entre elas, o autor justifica: "tentaria libertar-me da obcecação de à força ter de encaixar fatos empíricos em teorias preestabelecidas" (PAIS, 2003, p. 65). Portanto, o autor assume um posicionamento em relação às teorias da juventude, que é o das Culturas Juvenis, numa vertente antropológica das experiências cotidianas dos jovens. $O$ autor entende esse conceito como:

[...] um conjunto de símbolos específicos que simbolizam a pertença a um determinado grupo; uma linguagem com seus específicos usos, particulares rituais e eventos, através dos quais a vida adquire um sentido. Esses "significados compartilhados" fazem parte de um conhecimento comum, ordinário, cotidiano (PAIS, 2003, p. 70).

As Culturas Juvenis somente podem ser compreendidas, segundo o autor (2003), se incorporadas à realidade social, fazendo parte do universo simbólico das práticas do dia a dia.

Diante do exposto, podemos imaginar o quão é importante que a escola considere os jovens, suas manifestações e formas de organização. Como aponta Dayrell (2007), é preciso diminuir a distância entre o mundo juvenil e o mundo escolar, pois os jovens na sua diversidade apresentam características, práticas sociais, modos de vida, dentro de um universo simbólico todo próprio. A falta de valorização do jovem como sujeito cultural representa uma problemática que assola o interior das escolas de Ensino Médio no contexto atual.

A Educação Física no Ensino Médio, ainda tem grande ênfase na esportivização, de um modo geral, preocupa-se apenas com uma dimensão da disciplina, a socialização de conhecimentos técnicos sobre as modalidades esportivas. Abordada desse modo, com objetivo de cuidar apenas do "físico", acaba por oferecer práticas corporais acríticas, reproduzindo uma dicotomia histórica e que promove a ruptura entre corpo-mente.

Propomos uma Educação Física de ação-reflexão, problematizando as práticas da cultura corporal de movimento, presente nas culturas juvenis, que busca contribuir para que os jovensalunos se tornem mais satisfeitos, integrados, conscientes, se sentindo mais fortes e seguros em relação ao seu destino e ao das outras pessoas, para assim alcançar uma atuação social mais efetiva. As aulas oferecidas na escola parceira eram espaços de vivências significativas, de descobertas, debates, de produção de conhecimento e, principalmente, de reflexão crítica sobre a experiência. Isto possibilitava a abertura de novos espaços de diálogo, criando mecanismos para que os jovens pudessem se desenvolver integralmente. 


\section{OBJETIVOS}

Diante do exposto e dos estudos realizados sobre a temática, destacam-se os seguintes objetivos para a pesquisa:

- Investigar quais são, como são vivenciadas e compreendidas as manifestações das culturas juvenis relacionadas à cultura corporal de movimentos, pelos jovens de uma sala do Ensino Médio em uma escola pública na cidade de Presidente Prudente;

- Pesquisar de que forma a disciplina de Educação Física pode realizar um dialogo integrativo com as culturas juvenis no espaço escolar;

\section{METODOLOGIA}

A metodologia escolhida para a realização desta pesquisa é de natureza qualitativa, caracterizando-se como pesquisa-intervenção. Tal abordagem encontrou-se em perfeita harmonia com as expectativas da pesquisa, pois buscamos compreender principalmente, sobre as manifestações das culturas juvenis e sendo assim, a maiorias dos dados não são quantitativos, pelo contrário, são notados em meio aos acontecimentos, nas relações entre pares, nas conversas informais.

A adoção da metodologia qualitativa foi importante para este estudo, pois em lugar de elaborar generalizações do tipo estatístico, fizemos uma análise interpretativa e crítica do material coletado (ALVES, 1991). Essa metodologia nos permitiu compreender os fenômenos juvenis a partir da perspectiva dos participantes das intervenções, obtendo dados descritivos que só foram alcançados devido à interação entre pesquisador com a situação objeto de estudo. Visto que, há situações que não podem ser analisados de maneira quantitativa, há detalhes que não podem se delimitados, são simplesmente descobertos nos interstícios das relações estabelecidas entre pesquisador/professor e objeto de estudo/jovens-alunos.

\section{RESULTADOS}

Diante do exposto é possível inferir que as manifestações das culturas juvenis relacionadas à cultura corporal de movimento, dos jovens investigados não são homogêneas e nem estáticas. Não foi encontrado apenas um estilo, uma maneira de se vestir, de se expressar, de gosto, de preferência. Foram encontradas várias manifestações, jeitos de ser e estar no mundo, reunidos em torno de práticas variadas. Como exemplo, temos a tabela a seguir que trata do gosto musical dos jovens-alunos: 


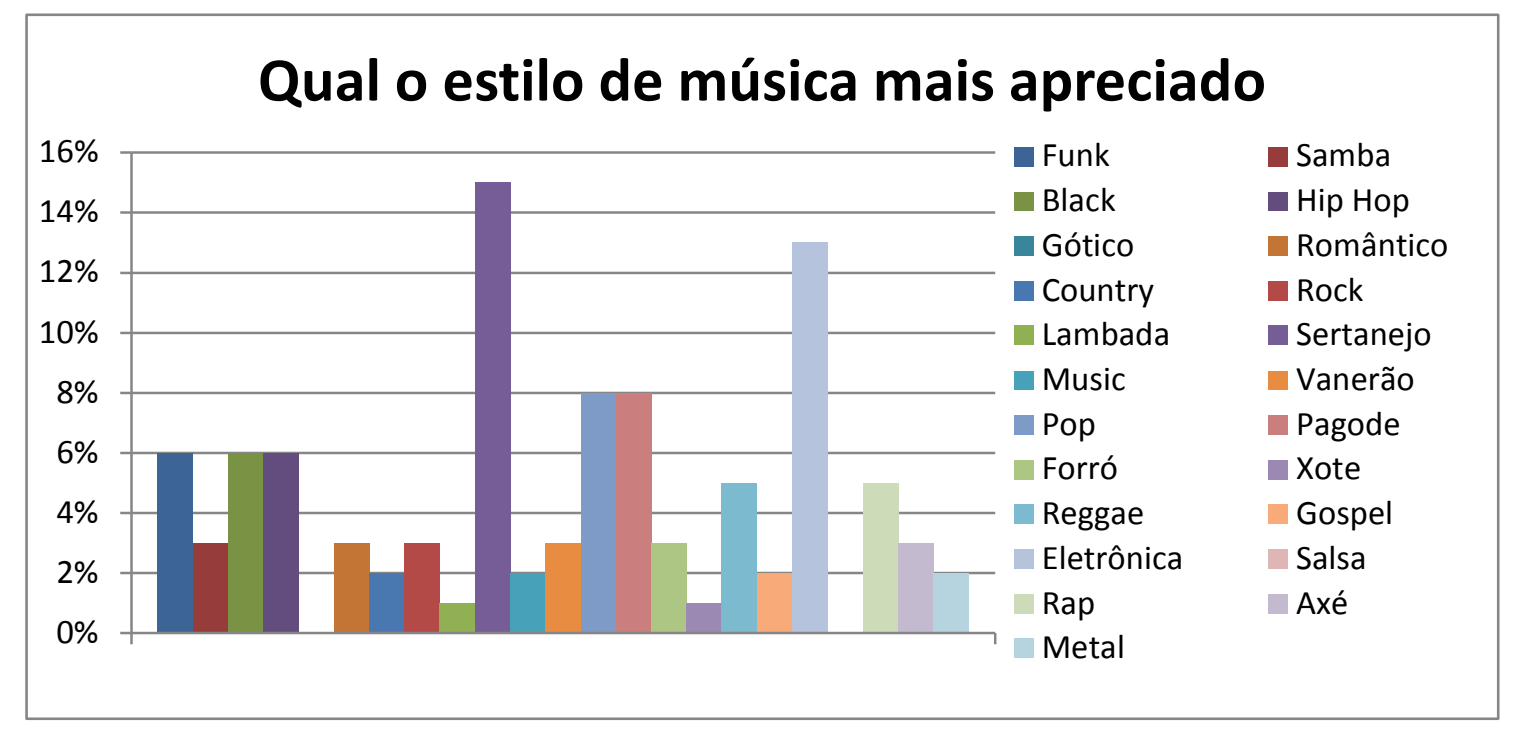

Também é possível afirmar que, nesta pesquisa, a disciplina de Educação Física pôde realizar um diálogo integrativo com as culturas juvenis no espaço escolar, na medida em que, ao procurar compreender o universo juvenil, possibilitou a interlocução entre o que era vivido pelos jovens no seu cotidiano e a prática efetivada nas aulas. Podemos notar claramente nas transcrições a seguir que dizem respeito à contribuição das intervenções no cotidiano escolar dos jovens-alunos:

-"Aprendemos a trabalhar em equipe e a se comunicar mais".

- "Contribuiu para a classe se unir mais não só nas aulas do CEPELIJ, mas em todas".

-"Foi um momento de descontração que ajudou na união da sala".

- "Para fazer novas amizades, ajuda a interação entre todos".

- "Contribuiu, pois a gente aprendeu a trabalhar em grupo".

- "Os alunos da sala se conheceram melhor".

- "Contribuiu para melhor interação e conhecimento de todos".

- "Contribuiu no conhecimento e desenvolvimento motor de cada aluno".

- "Contribuiu para a melhor convivência entre pessoas diferentes".

- "Em nosso relacionamento, ficou melhor".

- "Pra todos se divertir e também para unir todos".

-"Acho que contribuiu para convivência entre alunos na sala de aula".

- "Os alunos da sala passaram a ter um convívio melhor".

Esta aproximação com as experiências corporais vividas em outros contextos gerou práticas bem sucedidas por parte dos alunos, o que causou alegria, contentamento, bem estar e vontade de participar ativamente das aulas. 


\section{DISCUSSÃO}

Esta pesquisa contribuiu para que a escola fosse um pouco mais democrática (pelo menos nesta aula), apesar dos alunos retratarem melhorias no convívio da escola como um todo. Na medida em que a disciplina possibilitou o princípio da inclusão, que é a participação de todos em práticas bem sucedidas. Também, validou as diferentes culturas, de maneira que os jovens se sentissem incluídos, representados, em seus modos de vida, músicas, vestimentas, práticas corporais, entre outras.

No percurso que nos possibilitou educar nosso olhar e ver que de todas as informações colhidas nesta pesquisa, o mais significativo foi perceber que, com todo o jeito especial de ser dos jovens, muitas vezes maroto, bagunçado, dinâmico, companheiro, cada um é único, tem sua maneira de ser e precisa ser respeitado, acolhido e orientado para que tenha perspectivas nesta sociedade em que poucos têm todos os direitos. Assim, com certeza, daremos a nossa contribuição na construção de uma sociedade e de um mundo melhor, com mais oportunidades, mais humano, mais justo e mais igualitário.

\section{CONCLUSÃO}

Concluiu-se que, apesar dos obstáculos e problemas encontrados, é sempre possível despertar nos jovens alunos a capacidade de aprender e rever suas visões e representações de educação, de sociedade e de mundo. Portanto, é possível que as escolas sejam espaços de múltiplas vivências, local onde os jovens sejam capazes de se emocionar, de sentir, amar, agir, serem solidários, sonhar e de se realizarem como pessoa humana.

Enxergar o jovem com um olhar adulto também é necessário, porém, é preciso focá-lo com compreensão e questionamentos, para que se entenda que o que ele faz são formas histórico-culturais de entender, reagir e estar no mundo. Portanto, compreender as culturas da juventude, é uma meta que deve ser assumida pelos educadores e foi também o objetivo desta pesquisa. Nesta perspectiva, esta pesquisa foi fundamental para que fosse possível compreender o Ensino Médio, como um local mais acolhedor, mais dinâmico e humano, na formação de jovens mais felizes, autônomos e solidários.

É preciso trazer para dentro da escola as práticas das culturas juvenis, como: o teatro, a poesia, a tecnologia, a dança, a música, o esporte, a ginástica, as lutas, os jogos, a queimada, a peteca, as brincadeiras, o conto, entre outras. Práticas essas, não no campo da reprodução, da automação, da mecanização e padronização, mas no campo da linguagem, 
considerando-as repletas de códigos e representações que foram construídas culturalmente e socialmente. Uma contribuição que pode auxiliar para que a escola seja para o jovem um espaço mais representativo e que traga mais sentido, realização e alegria.

\section{REFERÊNCIAS}

ALVES, A. J. O planejamento de pesquisas qualitativas em educação. Cadernos de Pesquisa. São Paulo. Cortez. v.77, p.53-61. maio 1991.

CARRANO, P. Identidades Culturais Juvenis e escolas: arenas de conflitos e possibilidades. Diversia nำ, cidpa Valparaíso, abril 2009, pp. 159-184.

DAYRELL, J. "A escola 'faz' as juventudes? Reflexões em torno da socialização juvenil". Educação e Sociedade, Campinas, v.28, n.100, p. 1105-1128, out. 2007. http://dx.doi.org/10.1590/S0101$\underline{73302007000300022}$

FREIRE, P. Pedagogia do Oprimido. Rio de Janeiro: Paz e Terra. 12aed. 1983, 220p.

PAIS, J. M. A construção sociológica da juventude-alguns contributos. Análise Social, vol. XXV $(105-106), 1990\left(1 .^{\circ}, 2 .^{\circ}\right), 139-165$.

- Buscas de si: expressividades e identidades juvenis. In: ALMEIDA, M. \& EUGENIO, F. Culturas Jovens: novos mapas do afeto. Rio de Janeiro: Jorge Zahar Editor, 2006.

. Culturas Juvenis. Lisboa; Imprensa Nacional casa da Moeda, 2003.

REGUILLO, R. Las culturas juveniles: un campo de estúdio; breve agenda para La discussión. Revista brasileira de educação, no 23, p.103-118, mai./jun./jul./ago. 2003. 